\title{
When misinterpreting the Bible becomes a habit
}

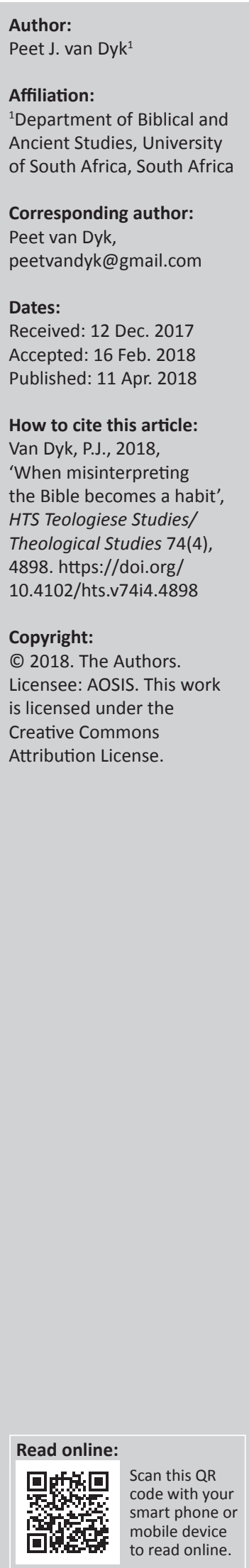

Ancient Near Eastern (ANE) texts should be interpreted against the background of the magicomythical cosmology of their time, and the Bible is no exception. Earlier scholars were, however, hesitant to recognise this reality as a result of disagreement over how to define myths and because of the problematic idealistic framework that they followed. This framework viewed biblical religion as superior to other ANE religions and thus devoid of myths and the belief in magic. It is, however, argued that the Bible contains both myths and a belief in magic and shares the overarching ANE cosmology. The incompatibility of the scientific cosmology and the magico-mythical cosmology of the ANE causes special problems for modern readers. To prevent modern readers from habitually falling back on their scientific cosmology, and thereby misinterpreting the Bible, it is suggested that a cosmological approach should form the basic framework for all biblical hermeneutics.

\section{Introduction}

The regularity and ease with which modern (post-Renaissance) readers misinterpret ancient texts is often underestimated by classical scholars. For example, when reading Samuel Butler's translation of the Iliad, the modern reader encounters the following passage at the beginning of Book IX: 'But Panic, comrade of blood-stained Rout, had taken fast hold of the Achaeans, and their princes were, all of them, in despair' [author's own italics] (Homer 2009). Except for the fact that the words Panic and Rout are capitalised by Butler, modern readers could easily be misled to think that Homer merely referred to a psychological state of mind among the Greek warriors. However, in the magico-mythical cosmology of ancient Greece the words $\Delta \varepsilon \tilde{\imath} \mu$ o $\zeta$ and $\varphi$ ó $\beta$ o $\zeta$ were the personal names of two minor Greek gods, who were supposed to roam battlefields and by their presence create panic and rout among soldiers. At the time of Homer, panic and rout on the battlefield were therefore never seen as natural psychological effects from warfare but always as being caused by the presence of these two gods. This interpretation is supported by the fact that Homer describes almost every earthly event during the Trojan War as the result of the interference of the gods (e.g. in the introduction to the Iliad, Homer explains the origin of the Trojan War as resulting from the fact that the god Apollo wanted to take revenge on the Greeks because they slighted his priest Chryses).

However, in line with the increasingly popular allegorical interpretation of the Iliad - a process that started with the philosophers in Ancient Greece - Butler chose to translate the names of the two gods merely as 'Panic' and 'Rout', thereby obscuring the fact that the text originally referred to two gods. ${ }^{1}$ He thereby perpetuated the incorrect idea that the text should not be taken literally but rather should be interpreted in a symbolic or allegorical way. The above example illustrates how easy it is for a modern translator (and therefore for his or her readers) to reduce the rich meaning of a text by disregarding its ancient magico-mythical cosmology.

The purpose of this article is to ask the question to what extent biblical scholars are also guilty of deliberately or unconsciously misreading the Bible, by ignoring the Bible's broadest cosmological assumptions and by replacing them with their own default modern suppositions thus making a habit of misinterpreting the Bible. The reason for such a switching of cosmologies is not necessarily because biblical scholars (especially historical-critical exegetes) are ignorant of the hermeneutical problems involved when reading ancient texts, but because one habitually reverts to one's own modern conceptual framework, except when consciously and consistently guarding against this error. What makes the danger of misinterpreting the Bible at the cosmological (and symbolic) levels so potentially calamitous is the fact that it is the broadest possible conceptual framework within which the text is interpreted, and thus it poses the largest scope for error.

1.It would therefore have been better to retain the Greek names of the two gods in the translated text and add that they were the gods who caused panic and rout on battlefields. 


\section{Gadamer's hermeneutical framework}

The hermeneutics of Gadamer and various reader-response approaches have convincingly shown that in the case of ancient texts, meaning can only be constructed when a continual interplay between text and reader takes place (Gadamer 1982:23, 292; Lang n.d.). According to Iser (1972:279), the convergence of text and reader brings the literary work into existence. Gadamer describes this process of understanding a text in terms of the horizon of the text versus the horizon of the reader and proposes that meaning can only be constructed by the fusion of these two horizons. He further emphasised the fact that one should constantly remind oneself of the fact that the horizon of an ancient text may be completely different from that of the modern reader.

Within reader-response circles it is often emphasised that meaning is constructed and not reconstructed (as assumed by most historical interpretations). In these circles, it is also frequently stated that it is impossible to reconstruct the original meaning of the text or the intention of the author (Thiselton 1998:38). I believe that both these notions are overstatements. In its most extreme form it would imply that no (or very little) communication between ancient author and modern reader is possible. The fact that it is in principle impossible to fully appreciate the original intention of an author does not mean that we can grasp nothing of it. Such absolutist views are typical of problematic binary thought.

Meaning can therefore only be constructed after the sense of the original text has (as far as possible) been reconstructed by the reader. Both the reconstruction of the original sense of the text and the subsequent construction of meaning by the modern reader are therefore necessary when interpreting the Bible. To use Gadamer's terminology: both the horizon of the text and the horizon of the contemporary reader should be considered when constructing meaning (Thiselton 1998:8): '... only if we respect the distinctiveness of the horizons of the text as against the distinctiveness of our own readerhorizon can a creative and productive interaction of horizons occur'.

Within the broad hermeneutical framework of Gadamer, several additional notions need to be clarified. One such notion is the idea of conceptual or cognitive frameworks.

\section{Cognitive frameworks and cosmologies}

It has been suggested by scholars that our perceptions and understanding of the world, and everything in it (including texts), largely depend on our constructs or conceptual frameworks (Berger \& Luckmann 1991). If this view is accepted, then it follows logically that such frameworks become extraordinarily important when interpreting texts. Along the same lines the Dutch scholar Ellen van Wolde has argued that biblical studies need to be reframed in terms of Cognitive Linguistics. Cognitive Linguistics argues that understanding of texts is the result of mental processing.
No understanding is possible without interpretation and such interpretation depends on (1) the way in which we categorise the world within our specific culture and (2) the conceptualisation of our individual mind (Van Wolde 2009:55).

Meaning is therefore facilitated by a vast network of interrelated knowledge that, inter alia, depends on culturally defined categorisation (Van Wolde 2009:55). Nyirenda (2013) summarises the importance of such conceptual frameworks for biblical exegesis as follows: 'For this reason, scholarship that discusses the probable conceptual frameworks is as critical as pedantic analyses of words, grammar, and syntax is for accurate exegesis'.

\section{Cosmology as an overarching cognitive framework}

Conceptual frameworks can be viewed as a hierarchy consisting of a series of smaller to larger (or more overarching) cognitive frameworks. The smallest framework would be the individual level of reference, unique to the author or reader. The next intermediate level of reference is the framework shared within a family, clan or various subgroups (e.g. gender, socioeconomic status, etc.). An even more inclusive framework is the shared cognitive frameworks of nations and religions, while the highest overarching meta-level could be termed a cosmology. ${ }^{2}$ The cognitive framework of a cosmology is shared by large cultural groups such as the Western world, traditional African communities or the Ancient Near East (ANE).

In its broadest sense, a cosmology can be defined as the sum of a community's shared beliefs and assumptions about the world. A cosmology thus acts as a broad conceptual framework in terms of which people interpret reality (Van der Merwe 2008:57). It includes not only beliefs about what the cosmos looks like but also how it functions in terms of causes and effects and, in the case of ancient societies, how the society is socially and politically structured. Ancient cosmologies were holistic in the sense that the natural and social environments were integrated within one supposedly interdependent system. For example, kingship was just as much part of the divinely ordained structure of the cosmos as the placements of the stars. Heavenly and earthly phenomena were also often perceived as mirror images of one another (Fisher 1965). For example, earthly temples were perceived as mirror images of the heavenly temple of the god(s).

\section{Literary analysis and cognitive frameworks}

From the discussion above, it follows that any hermeneutical analysis of texts ideally should pay attention to all the referential levels of a text, ranging from the smallest unique cognitive framework of the author to the broadest cosmological framework shared by the larger community within which the text was produced. However, this seldom happens, especially when author and reader share the same cultural, religious and

2.1 will use the term 'cosmology' not only to refer to a spatiotemporal universe but primarily as an interpretative framework or a 'significant' (rather than a symbolic) universe (see Van Dyk 2011:422-444) 
cosmological background, because it is assumed that author and reader would automatically be 'on the same station'. For this reason, modern critics of contemporary texts tend to pay little attention to the cosmology of the text but rather stress the personal conceptual framework, unique to the author.

However, in cases where author and reader do not share the same meta-cognitive framework (i.e. cosmology), it becomes extraordinarily important that both cognitive frameworks be given deliberate and constant attention, because if there is a communication gap on this meta-level it can cause complete misinterpretation of the text. It is especially critical to take cognisance of the cosmologies of text and reader when the two cosmologies are largely incompatible. This brings us to the question to what extent the magico-mythical and the scientific cosmologies are compatible.

\section{Magico-mythical cosmologies versus our scientific cosmology}

Like all pre-scientific cosmologies, the ANE cosmology emphasised supernatural causes and effects. One should, however, realise that the distinction between the so-called natural versus supernatural forces is a modern distinction (Walton 2009:21). In ancient pre-scientific cosmologies nothing was regarded as secular, but everything was perceived as being influenced by the supernatural. That is, all events on earth were directly or indirectly attributed to either personal supernatural forces (i.e. the gods) or to non-personal supernatural forces (i.e. magical powers).

\section{The importance of magic}

Religion and the belief in magic are based on the same basic idea, that is, that supernatural forces play a major causal role in the cosmos. An absolute distinction between religion and magic is therefore untenable, as is the earlier idealistic and evolutionary scheme of Edward B. Tylor (2010) and James G. Frazer (1957) that suggested that the so-called higher religions succeeded in ridding themselves from all beliefs in magic. For example, the important (if not central) role that magic played in ancient Egyptian religion was highlighted by Geraldine Pinch (2009), while its equal importance in ancient Mesopotamia was well documented by King (2000). The belief in magic and its function within pre-scientific cosmologies should therefore never be underestimated.

The logic of sympathetic magic maintains that physical semblance and contagion may link an object or place to a supernatural force or deity (Frazer 1957:14). This implies that an image of a god (i.e. its physical semblance) was not merely seen as a symbol of the god (as modern people would assume) but that it was magically linked to the god: That is, when kneeling in front of the holy image of a god, worshippers believed that they were somehow transported to the real presence of the god.

Similarly, when a god or spirit revealed itself at a certain place, such a locality became holy as a result of contagion by the presence of the god. The specific place was thus considered to be holy and magically linked to the god and the heavens thus acting as a portal or window to the heavens (Van Dyk 2009). Temples and altars were therefore built at such holy places where the god revealed him- or herself, because this ensured successful future communication with the god.

Names were also believed to be powerful vessels of magic. Nothing could exist without being named first. For example, at the beginning of the Enuma Elish it is stated that the heavens and the earth did not exist, because they had not yet been named. Analogous to this, the power of a god was contained within his or her secret name (King 1902). In the Egyptian story of Re ('Story of $\mathrm{Re}^{\prime}$, n.d.), Recreates the first gods by naming them. It is also stated in the Enuma Elish that the power of the god Marduk was contained within his name.

\section{Spiritualisation of the cosmos}

Another idea, which was typical of pre-scientific cosmologies (including the ANE), was the spiritualisation and personalisation of the whole cosmos (i.e. animism). Animism assumes that all living and many inanimate things have indwelling spirits (Tylor 2010). The reverse side of this belief is that all spirits or forces have a physical manifestation. For example, in ancient Egypt one of the physical manifestations of the god Thoth was the Sacred Ibis. The sun was also never seen as a mere physical object but always as the physical manifestation of the sun god (e.g. Re in Egypt, Utu in Sumer and Shamash in Assyro-Babylonia). All the important cosmic structures were in the same way associated with the so-called elemental gods, implying a spiritualisation of the whole cosmos. For example, in Heliopolis (in ancient Egypt) the four gods Shu, Tefnut, Geb and Nut represented the basic elements of the earth - air, water, earth and sky, respectively (Vendel n.d.).

In agreement with the religious nature of the ANE cosmology, the idea existed that pre-existing chaotic forces (mostly perceived as elemental gods) were subdued during creation. In this way the cosmos was ordered by the wisdom of the creator god and each god received his or her proper place and function. Differentiation through separation was perceived as being especially important in establishing such created order. Some scholars have therefore argued that our modern material concept of creation (i.e. creating something material out of nothing) is not applicable to the cosmogony of the ANE. Walton (2009:25-26) has argued that creation was not seen in material terms but in terms of function, and Van Wolde (2009:367-368) has suggested that the Hebrew term ברא should not be viewed as making something new (i.e. create) but as differentiation through separation.

For example, on the fifth tablet of the Enuma Elish we read how Marduk gave all the gods their proper stations and linked them to their heavenly manifestations, that is, the stars of the Zodiac and the moon:

$\mathrm{He}$ (Marduk) made the stations for the great gods;

The stars, their images, as the stars of the Zodiac, he fixed.

He ordained the year and into sections he divided it; 
For the twelve months he fixed three stars.

After he had ... the days of the year ... images, He founded the station of Nibir [the planet Jupiter] to determine their bounds;

That none might err or go astray,

He set the station of Bel and Ea along with him.

He opened great gates on both sides,

He made strong the bolt on the left and on the right.

In the midst thereof he fixed the zenith;

The Moon-god he caused to shine forth, the night he entrusted to him.

He appointed him, a being of the night, to determine the days. (King 1902)

\section{Purposefulness of the world}

Linked to the idea that the whole cosmos was structured or designed by the creator god was the concept of teleology or the purposefulness of the cosmos. This implied that the cosmos had a built-in purpose. Linked to this was the idea that the gods controlled the day-to-day history and fate of the Earth and the people. For example, in the Sumerian poem Enki and the World Order the day-to-day destiny of the world was decided on the eastern horizon by the gods Enki and Enlil, just before sunrise:

I [Enki] am he who decrees the fates with Enlil in the 'mountain of wisdom'. He placed in my hand the decreeing of the fates of the 'place where the sun rises'. (Kramer 1963:175; Woods 2009:186)

\section{Cosmology and myth}

In the pre-scientific era, cosmologies were exclusively conceptualised through the narration of a community's mythical literature. The term 'magico-mythical' ${ }^{\prime 3}$ can therefore be used to refer to pre-scientific cosmologies, because it focuses on the two critical elements that distinguish it from our post-Renaissance, post-Enlightenment cosmology - that is, on (1) the fact that such cosmologies were based on a mythical narrative rather than a scientific narrative and (2) the assumption of a religious cosmos, where a system of supernatural causes and effects is embedded within such a cosmology.

\section{The scientific cosmology}

It should be appreciated that when our current scientific cosmology started to develop during the time of the Renaissance and Enlightenment in Western Europe, it was posed as a conscious alternative to the magico-mythical cosmologies that preceded it up to the end of the Middle Ages. In stark contrast to the preceding religious and supernatural assumptions of magico-mythical cosmologies, our current scientific cosmology deliberately wants to exclude supernatural causation and thus wishes to explain the universe only in terms of natural causes and effects. The so-called ultimate causes, such as the miraculous intervention of God or magic, are thus either ignored or deemed as mere superstitions that should be abandoned (Gay 1966:66). The scientific cosmology therefore wants to de-spiritualise the cosmos by excluding all spiritual forces.

Another way in which our scientific cosmology differs from the preceding magico-mythical ones is that it challenges the idea that life and the cosmos has a built-in purpose. Notwithstanding the many attempts to try and prove that biological evolution showed progression towards humans as the purpose of biological evolution, or that it can be illustrated that the cosmos shows a higher and purposeful design, all such attempts are either circular or seriously flawed (Hawking \& Mlodinow 2012:164; Williams 1966:35-46). Therefore, although the purposefulness of the cosmos was taken for granted in magico-mythical cosmologies, this is no longer the case in the scientific cosmology.

\section{The fallacy of concordism}

The next question that needs to be answered is whether the biblical cosmology in some 'miraculous' way anticipated our current scientific cosmology. If this was indeed the case it would imply that the Bible is not necessarily incompatible with the scientific cosmology. Consciously or unconsciously the idea of concordism (the belief that the Bible must agree - or be in accord with - all the major findings of contemporary science) has led some fundamentalist biblical scholars to argue that the biblical cosmology is compatible with science and that faith and science therefore do not need to be at war with one another (Walton 2009:19). Such sentiments are often expressed when scholars attempt to fit evolutionary thoughts into the biblical creation accounts or harmonise biblical concepts with known scientific knowledge.

Concordism is, however, untenable and needs some fancy footwork and a large dosage of wishful-thinking to be maintained, especially when confronted with the dated description of the cosmos within the Bible. I therefore agree with the view expressed by Walton (2009) that Genesis 1 (and the rest of the Old Testament [OT]) reflects the ancient cosmology of the ANE:

... [Gen 1] does not attempt to describe cosmology in modern terms or address modern questions. The Israelites received no revelation to update or modify their 'scientific' understanding of the cosmos ... they thought about the cosmos in much the same way that anyone in the ancient world thought ... (p. 16)

Any attempt to interpret the Bible in such a way that it would be compatible with science should therefore be viewed with the utmost suspicion. In most cases, such interpretation wilfully ignores the context of the ANE. In those rare cases where the biblical cosmology and our scientific cosmology do agree, it should be seen as fortuitous rather than a kind of special revelation by God that transcended the cosmology of its time.

\section{Is the biblical cosmology unique?}

How similar were the cosmologies of the ANE and the Bible? Were they sufficiently similar that one can speak about one 
overarching magico-mythical cosmology of the ANE, which would include the biblical one? Over the centuries, various biblical scholars have argued that the magico-mythical cosmology of the ANE differs in crucial ways from that of the Bible. Arguments against classifying the biblical cosmology as magico-mythical in nature centred mainly around the issues of myth and magic in the Bible.

\section{Are there myths in the Bible?}

Many biblical scholars have strongly reacted against the idea of Rudolf Bultmann (1989) that the Bible is basically mythological in nature (i.e. it shares its magico-mythical cosmology with the ANE). Bultmann proposed that modern readers should first de-mythologise the Bible before it could become meaningful to them. It is therefore necessary that the implications of Bultmann's views be investigated anew by biblical scholars. Can mythological elements within the Bible really be dismissed as mere remnants of myths or as mythopoetic imagery that should not be taken literally?

The first issue, which barred many biblical scholars from sufficiently recognising the many similarities between the biblical and ANE cosmologies, was the various ways in which myths and mythology were defined by biblical scholars. As can be appreciated, each scholar's definition of the term largely determined whether myth would be recognised as an appropriate category of literature within the Bible. Since the late 1700s, when the mythical school of Eichhorn and Gabler first introduced the concept of myth into OT studies, the idea of biblical myths has been widely debated, with the debate swinging between the two extremes of either recognising or denying the usefulness of the concept (Kraus 1982:147-151). Three misconceptions about myths have been instrumental in making scholars sceptical about the possibility of accepting the presence of myths in the Bible: (1) the popular concept of the term 'myth' as denoting an untrue story; (2) the widespread popularity of Gunkel's definition of myths as Göttergeschichte [history of the gods] (Gunkel 1966) and (3) the cyclic concept of time in myths, as opposed to the assumed historical or linear view of time in the Bible. The problems with each one of these misconceptions will be discussed next.

Firstly, the popular definition of myths as untrue stories is problematic because it views myths exclusively from a modern (post-Enlightenment) perspective. Although the truth or correctness of ancient myths cannot withstand the scrutiny of modern science, this modern view of myth is in stark contrast to the view of ancient audiences, who firmly believed that myths were the highest form of truth and were an accurate reflection of reality (Dundes 1984:1). Defining myths therefore as untrue would violate the way in which they were originally understood.

Secondly, the popular view of Hermann Gunkel that myths are basically polytheistic in nature (i.e. a history of the gods) and that all true myths should hence be excluded from the largely monotheistic OT could rightly be criticised on two grounds: (1) John Rogerson (2014) has convincingly argued that such a definition of myths is unnecessarily narrow. One can add to this the argument that such a narrow definition was used almost exclusively by biblical scholars, further suggesting its limited usefulness. One can rightly ask whether this view of myths became so popular among theologians exactly because it gave them a reason to exclude a supposedly offensive concept from the Bible. (2) Even if one accepts with Gunkel the basically polytheistic nature of myths, one still needs to deal with the problematic concept of monotheism and its applicability especially to the earlier strata of the OT. It is often not clear if the OT completely denied the existence of other gods (especially in its earlier strata) or merely stripped from them any significant power and thus portrayed it as ridiculous if the Israelites were to worship them (Smith 2001:206; Vriezen 1974:34). Many OT scholars therefore accept that, at least in the earlier strata of Israel's religion, the existence of other gods was not necessarily denied (Smith 2001). At least, the presence of other supernatural creatures in the OT, such as 'the sons of God' (Gn 6:2, Job 1:6), Leviathan, Behemoth, various spirits and the introduction of Satan in the latter parts of the OT, should be viewed as a departure from strict monotheism. This is, however, not to deny the fact that Israel's tendency towards monotheism would naturally have led them to a more de-personalised perception of the cosmos and hence the OT's near-silence about any cosmic battles between various supernatural powers during creation.

Thirdly, the common assumption by biblical scholars that myths should be defined in terms of their cyclic view of time, while the Bible was supposed to have a linear historical view of time, can also be challenged on several grounds. Driven by the mistaken idealistic notion that the so-called higher religions (e.g. the Bible) overcame the more 'primitive' cyclic ideas of mythologies, biblical scholars proposed that the mythological concept of time was completely replaced by the uniquely historical framework of the Bible. The Bible was thus assumed to be superior to ANE mythology and its cosmology (Hasel 1974:84). Such an idealistic evolutionary view of the development of religions, on which the above arguments depend, is nowadays rightly criticised by many scholars of religion (see the earlier discussion about magic).

The above view of history and myth as excluding alternatives can further be criticised because it depends on binary logic, which seduced scholars to view myth and history as mutually exclusive categories. Such binary logic has been criticised by post-Structuralist philosophers such as Derrida and Bass (2002:351-370), who suggested that we should deconstruct Westernised thinking, which tends to construct everything in terms of binary opposites, where one term is always given preference over its opposite. Fuzzy logic also criticised binary logic for its lack of accuracy, that is, its forcing reality into alternative black and white categories without considering the possibility of various shades of grey (Kosko 1993:3-17).

The absolute distinction between history and myth is therefore questionable on the following grounds: (1) myths (like modern critical history) were assumed to be true, that is, to 
accurately reflect past reality. The distinction between history and myth is therefore a post-Enlightenment idea. Before the advent of critical historiography all sacred narratives about the past (i.e. myths) were assumed to be history in the sense that we would define it today. (2) Both history and myth function as cognitive frameworks against which reality is interpreted. (3) The idea that myths viewed time as more cyclic in nature, while the so-called biblical history saw past events in a more linear fashion, is probably an overstatement of the case. At closer inspection, myth does not exclusively view time as cyclic, nor is biblical history devoid of any cyclic concepts of time. For example, the OT deluge narratives portray the deluge as a reversal of creation with the dissolution of the separation between the waters and the dry ground and the reintroduction of chaos. The flood was therefore portrayed as a type of un-creation and re-creation, confirming that the forces of chaos can sometimes overwhelm the order of creation - as assumed by the cyclic concept of time in most ANE myths (Blenkinsopp 2011:34). At the most, one could say that the OT may have viewed the cosmos as a more stable entity than most of the other myths of the ANE.

Ancient Near Eastern mythology is also not completely devoid from a linear timeframe: one generation followed another, and dynasties came to an end and were followed by their successors, hence the emphasis on genealogies and king lists in the ANE (e.g. the Sumerian king list; Walton 1990:129). The cosmos was also not regularly destroyed and re-created in ANE myths, but the primordial events were seen as foundational to the events that followed them. A more accurate view of the time concept of both the ANE and the OT would therefore be to acknowledge that both views included cyclic and linear concepts of time. It can therefore be concluded that rendering history and myth as two exclusive categories is not only an inappropriate application of binary logic but is also an unacceptable modern distinction that would be alien to the ancient world.

The supposed uniqueness of the biblical cosmology, when compared to that of the ANE, also became increasingly difficult to maintain in light of the large number of mythological texts discovered by archaeologists in the ANE from the middle of the 1800s. The often-startling similarities between some of these ANE mythological texts and the OT have led to the well-known Babel-Bibel controversy toward the end of the 1800s: On the one side, scholars such as Friedrich Delitzsch claimed that many biblical narratives directly depended upon their Babylonian antecedents displaying little if any originality. Vehemently opposed to his group was another group of scholars who desperately wanted to minimise these similarities by explaining them away or by suggesting that biblical narratives were composed as deliberate polemics against the mythical concepts of the ANE (Hasel 1974:81). In a sense, this controversy continued until late into the 1900s with scholars such as Hasel and Westermann still arguing in the 1970s that the biblical accounts of creation (especially Gn 1) should be viewed as deliberate polemics against the ANE cosmology, which typically portrayed creation as the result of a cosmic battle between the gods of chaos and the creator god (Hasel 1974; Westermann 1976).

Both abovementioned extreme views are probably overstatements of the case. Rather than seeing the biblical accounts as directly dependent upon ANE myths (i.e. as either agreeing with them or as a polemic against them) many scholars now accept that the similarities between ANE and OT myths should rather be seen in terms of a shared cosmology, without giving preference to any given culture or by pronouncing one account (e.g. the Babylonian creation account) more authentic than others. However, the many similarities between the various myths of the ANE and the OT should not blind us to the many differences between them, because each religious community adapted the cosmology of the ANE to their own unique religion and gods. Even within ancient Mesopotamia there were at least three main cultural and religious strands, while in Egypt at least four different theologies (Heliopolitan, Memphis, Theban and Hermopolitan) can be distinguished, depending on date and locality (Hasel 1974:81-84). Van Wolde (2009:356) acknowledges this by saying that cultural categorisation is dynamic and therefore adjusted to changed circumstances, but '.. it is also solid in that it is shared by a social group and consolidated in conventions and prototypical structures and scenarios'.

When viewing cognitive frameworks as multilayered constructs (as argued earlier), it becomes possible to accommodate the many similarities between the biblical and ANE religious narratives at the meta-level of a cosmology, while acknowledging the uniqueness of each religion at lower levels. Although the cosmology of the ANE was adapted to the unique beliefs of each nation, the basic ideas about the cosmos were shared to such an extent that one could speak about the cultural unity of the ANE in terms of its overarching cosmology. Some of the shared cosmographical concepts were inter alia the idea of a flat earth disc, resting on pillars in the primeval flood, and the notion of a dome (firmament) that separated the earth from the heavenly waters above it (Wright 2002:ix, 46, 110-118).

\section{The belief in magic}

More recently, biblical scholars have convincingly challenged the idea that the belief in magic is absent in the Bible (Klutz 2003; Labahn \& Peerbolte 2007). As suggested earlier, the belief in magic was basic to the cosmology of the ANE. It was further argued that religion and magic make the same assumptions regarding supernatural causes and effects and that no absolute distinction between religion and magic could therefore be made.

Earlier biblical scholars, however, largely ignored or denied the possibility that beliefs in magic could still be discerned within the Bible. They based their views largely on the general 
hostility of the Bible toward manipulative magical practices. These would include, inter alia, the making of images and worshipping them, worshipping in high places and pronouncing the sacred name of YHWH. One should, however, ask if these prohibitions should be interpreted as a denial of the existence of magic or if they were rather based on the assumption that magic was real but that any attempted manipulation of $\mathrm{YHWH}$ through magic would be demeaning to God and thus unacceptable within Yahwism.

However, the fact that the manipulation of YHWH through magic was unacceptable does not imply that magic or the belief in magic was absent from the Bible. For example, the Priestly author $(\mathrm{P})$ described the creation in Genesis 1 as creation by merely saying a word or calling the name of the element to be created. This may suggest the possibility that God created the universe by pronouncing magical words in the same way that the god Marduk used magical words in the Enuma Elish to destroy and then to recreate a garment (Westermann 1976:154). It is interesting to note that, although Westermann acknowledged this fact and even recognised that the wording in Genesis 1 did not preclude such a magical interpretation, he nonetheless rejected such a possibility. According to him P did not have what would amount to a worldview and did not share a cosmology with the ANE. The so-called historical context of the Priestly author would therefore (according to Westermann) preclude the possibility of such a magical interpretation (Westermann 1976:154-160). One can, however, rightly ask to what extent these views of Westermann were determined by a certain theological bias and by the untenable belief in the non-mythical nature of the OT.

The way in which holy places of worship were selected in the OT may further suggest a magical cosmology: in agreement with the logic of sympathetic magic, specifically contagion, all the major places of worship of the Israelites were selected because God revealed his presence there. See for example how Bethel (Gn 28:11-19), Gibeon (1 Kgs 3:4) and Jerusalem (1 Chr 21:15-28) became holy sites and were perceived as places magically linked to God's home in the heavens:

By blessing a place God establishes a magical link (a form of contagion), making it holy and a fit place where sacrifices could be offered. The presence of God in a sacred place was seen as more special than his general omniscience within profane space. This fits in with the concept that the tabernacle was magically linked to God and thereby became a real portal to the heavens. (Van Dyk 2009:431)

\section{Summary}

It can be concluded that the OT cosmology shared not only many similarities with the cosmology of the ANE but was also mythical and magical in nature. It can therefore rightly be called a magico-mythical cosmology, like all other prescientific cosmologies, including that of the ANE. At the metacosmological level there were thus sufficient similarities to speak about one overarching cosmology of the ANE, which included that of the Bible (Liverani 2014:8). This is not to deny that at lower levels one can identify many unique features and adaptations by the Israelite religion.

\section{Rethinking biblical hermeneutics}

More recently, scholars like Walton (2009) and Van Wolde (2009) reaffirmed the importance of taking the cosmological assumptions shared by the Bible and the ANE more seriously. This implies that these shared cognitive frameworks are not mere curiosities that can occasionally be mentioned in passing. Cosmology should become the focal point of all biblical hermeneutics: It is on the canvas of the cosmological assumptions of the biblical text that all quests for meaning should be painted, lest we forget how much our modern cosmology differs from the magico-mythical cosmology of the Bible.

It is no overstatement to say that there exists a fundamental clash between the magico-mythical cosmologies of the ancient world and the scientific cosmology of contemporary Westernised Bible readers. As suggested earlier, such a clash in cosmologies may be the cause of serious misinterpretation of the biblical text. It is understandable that modern readers tend to habitually fall back on their default frame of reference (i.e. their scientific cosmology), unless they are constantly reminded that the ancient text of the Bible does not share their modern cosmological assumptions. When such a switch back to one's own default cosmology takes place, it may result in a critical reduction in meaning of the biblical text. This reduction in meaning is most often an unconscious process of 'filtering out' those elements that do not fit the reader's own default frame of reference. The importance of consistently and deliberately taking cognisance of the possible differences between the cosmology of the biblical text and the cosmology of the modern reader can therefore hardly be overemphasised. One example in biblical exegesis of how exegetes have often misinterpreted an OT text is the interpretation of the rich, complex term רוח אלהים [spirit of God]: in this case the fact that modern critics have habitually fallen back on their modern scientific cosmology resulted in the undesired reduction in meaning of the term, because they failed to appreciate the inseparable link that existed between the three meanings, that is, spirit, breath and wind, within pre-scientific cosmologies (see Van Dyk 2017 for a discussion of this example).

I therefore wish to propose a cosmological approach to biblical exegesis, not as just another approach parallel to the myriad of other perspectives, but as a fundamental way in which the meaning of the Bible should be (re)constructed.

\section{Acknowledgements Competing interests}

The author declares that he has no financial or personal relationships which may have inappropriately influenced him in writing this article. 


\section{References}

Berger, P.L. \& Luckmann, T., 1991, The social construction of reality: A treatise in the sociology of knowledge, Penguin, Harmondsworth.

Blenkinsopp, J., 2011, Creation, un-creation, re-creation: A discursive commentary on Genesis 1-11, T\&T Clark, New York.

Bultmann, R., 1989, New Testament and mythology and other basic writings, transl. S.M. Ogden, Fortress Press, Philadelphia, PA.

Derrida, J. \& Bass, A., 2002, Writing and difference, University of Chicago Press, Chicago, IL.

Dundes, A. (ed.), 1984, Sacred narrative, readings in the theory of myth, University of California Press, Berkeley, CA.

Fisher, L.R., 1965, 'Creation at Ugarit and in the Old Testament', Vetus Testamentum 15, 313-324. https://doi.org/10.1163/156853365X00189

Frazer, J.G., 1957, The golden bough: A study in religion and magic, McMillan, London.

Gadamer, H.-G., 1982, Truth and method, Crossroad, New York.

Gay, P., 1966, The enlightenment: An interpretation. The rise of modern paganism, Weidenfeld \& Nicolson, London.

Gunkel, H., 1966, Genesis, 7. Aufl., Vandenhoeck \& Ruprecht, Göttingen.

Hasel, G.F., 1974, 'The polemic nature of the Genesis cosmology', The Evangelical Quarterly 46, 81-102.

Hawking, S. \& Mlodinow, L., 2012, The grand design, Bantam Books Trade Paperbacks, New York.

Homer, 2009, The lliad of Homer, transl. S. Butler, The Project Gutenberg EBook.

Iser, W., 1972, 'The reading process: A phenomenological approach', New Literary History 3(2), 279-299. https://doi.org/10.2307/468316

King, L.W., 2000, Babylonian Magic and Sorcery: Being 'the Prayers of the lifting Hand' S. Weiser, York Beach, ME.

King, W.W., 1902, 'The seven tablets of creation', viewed 14 November 2017, from http://www.sacred-texts.com/ane/stc/index.htm

Klutz, T. (ed.), 2003, Magic in the biblical world: From the rod of Aaron to the ring of Solomon, T \& T Clark, London.

Kosko, B., 1993, Fuzzy thinking. The new science of fuzzy logic, Harper Collins Publishers, London.

Kramer, S.N., 1963, The Sumerians. Their history, culture, and character, University of Chicago Press, Chicago, IL.

Kraus, H.-J., 1982, Geschichte der historisch-kritischen Erforschung des Alten Testaments, 3., Aufl., Neukirchener Verlag, Neukirchen-Vluyn.

Labahn, M. \& Peerbolte, B.J.L. (eds.), 2007, A kind of magic: Understanding magic in the New Testament and its religious environment, T \& T Clark, London.

Lang, C., n.d., 'A brief history of literary theory', viewed 26 October 2015, from https:// www.xenos.org/essays/brief-history-literary-theory
Liverani, M., 2014, The ancient near East: History, society and economy, transl. S. Tabatabai, Routledge/Taylor \& Francis Group, London.

Nyirenda, M., 2013, 'Theological interpretation and translation reception: Translating "Spirit of God" in Genesis 1.1-2', The Bible Translator 64(3), 284-299. https://doi. org $/ 10.1177 / 2051677013507215$

Pinch, G., 2009, Magic in Ancient Egypt, University of Texas Press, Austin.

Rogerson, J.W., 2014, “"Myth” in the Old Testament', in D.E. Callender (ed.), Myth and scripture. Contemporary perspectives on religion, language, and imagination, pp. 15-25, SBL Press, Atlanta, GA.

Smith, M.S., 2001, The origin of biblical monotheism. Israel's polytheistic background and the Ugaritic texts, Oxford University Press, New York.

Thiselton, A.C., 1998, New horizons in hermeneutics: The theory and practice of transforming biblical reading, Zondervan Publishing House, Grand Rapids, MI.

Tylor, E.B., 2010, Primitive culture: Researches into the development of mythology, philosophy, religion, art, and custom, Cambridge University Press, Cambridge.

Van der Merwe, J.C., 2008, 'The relevance of worldview interpretation to health care in South Africa', in Health knowledge and belief systems in Africa, pp. 55-66, Carolina Academic Press, Durham, NC.

Van Dyk, P.J., 2009, 'Creation, temple and magic. A magico-mythical reading of Genesis 1', Old Testament Essays 20(2), 422-436.

Van Dyk, P.J., 2011, 'Significant versus symbolic universes - Sorting out the terminology', Journal for Semitics 20(2), 422-444.

Van Dyk, P.J., 2017, 'The spirit of God, or is it?', HTS Teologiese Studies/Theological Studies 73(3), a4670. https://doi.org/10.4102/hts.v73i3.4670

Van Wolde, EJ, 2009, Reframing biblical studies: When language and text meet culture, cognition, and context, Eisenbrauns, Winona Lake, IN.

Vendel, O., n.d., 'The spirits of nature. Religion of the Egyptians', viewed 14 November 2017, from http://www.nemo.nu/ibisportal/0egyptintro/1egypt

Vriezen, T.C., 1974, Hoofdlijnen der theologie van het Oude Testament, vierde druk, Veenman en Zonen, Wageningen.

Walton, J.H., 1990, Ancient Israelite Literature in its cultural context: A survey of parallels between Biblical and Ancient Near Eastern Texts, Zondervan Publishing House, Grand Rapids, MI.

Walton, J.H., 2009, The lost world of Genesis One: Ancient cosmology and the origins debate, IVP Academic, Downers Grove, IL.

Westermann, C., 1976, Genesis 1 - 11, 2. Aufl., Neukirchener Verlag, NeukirchenVluyn.

Williams, G.C., 1966, Adaptation and natural selection: A critique of some current evolutionary thought, Princeton University Press, Princeton, NJ.

Woods, C., 2009, 'At the edge of the world: Cosmological conceptions of the eastern horizon in Mesopotamia', Journal of Ancient Near Eastern Religions 9(2), 183-239. https://doi.org/10.1163/156921109X12520501747912

Wright, J.E., 2002, The early history of heaven, Oxford University Press, New York. 